
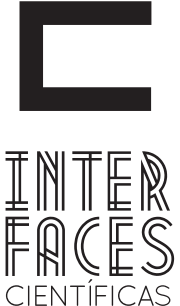

HUMANASE SOCIAIS

\title{
SENSIBILIZANDO PARA O TURISMO: RELATO DE EXPERIÊNCIA SOBRE UM INSTRUMENTO PEDAGÓGICO
}

Ilka Maria Escaliante Bianchini ${ }^{1}$

Letícia Bianca Barros de Moraes Lima ${ }^{3}$
Luis Carlos Gonçalves ${ }^{2}$

Josael Bruno de Souza Lima ${ }^{4}$

\section{RESUMO}

Conhecer os benefícios de uma atividade econômica e as possibilidades de qualificação em curso técnico ofertado na sua região pode despertar o interesse dos discentes na escolha da profissão, o respeito pelo meio ambiente e pelo turismo e ainda promover um método de ensino participativo. Este consiste em um relato de experiência sobre o projeto de extensão Sensibilizando para o Turismo, desenvolvido no Instituto Federal de Alagoas no campus Marechal Deodoro por uma docente e três discentes dos cursos técnicos Integrados de Guia de Turismo e Meio Ambiente. 0 projeto foi desenvolvido em 2012 e aplicado em quatro escolas do entorno do Instituto Federal de Alagoas. Inicialmente foram realizadas pesquisas bibliográficas e entrevistas que resultaram na formatação de oficina sobre Turismo e Meio Ambiente. As oficinas aconteceram em escolas da rede pública selecionadas com a participação de discentes dos oitavos e nonos anos.

\section{PALAVRAS-CHAVE}

Educação. Meio ambiente. Turismo. 


\section{ABSTRACT}

To know the benefits of an economic activity and the chances of qualifying in a technical course offered in a mentioned region and how it can arouse students' interest in choosing their profession, the environment and tourism respect and also promotes a participatory method of teaching. It consists of an experience report about an extension project named "Raising Awareness for Tourism", developed at Federal Institute of Alagoas - in Marechal Deodoro campus, by a professor and three students of Integrated Technical Courses of Tourism Guide and En- vironment. The project was developed in 2012 and it was implemented in four schools nearby Federal Institute of Alagoas. Firstly, it was made literature researches and interviews that resulted in a workshop about Tourism and Environment. The workshops were held in public schools chosen with the students of eighties and nineties grades' participation.

\section{KEYWORDS}

Education. Environment. Tourism.

\section{RESUMEN}

Conocer a losbeneficios de una actividad económica y lasopciones de cualificaciónenlacarrera técnica enlaregión donde se vive puedeayudar a despertar elinterés de los discentes enlaelección de laprofesión, elrespectoconelmedio ambiente y por el turismo y todavía promover una metodología de enseñanza participativa. Este articulo presenta un relato de una experiencia sobre elproyecto de extensión Sensibilizando para o Turismo, desarrolladoenel Instituto Federal de Alagoas enel campus Marechal Deodoro, por una docente y cuatro discentes de lacarrera técnica Integrada de Guía de Turismo y Medio ambiente. El

proyectofuedesarrolladoenelaño 2012 com La aplicación em cuatro escuelas regulares alrededor del Instituto Federal de Alagoas. Primeramente fueron realizadas pesquisas bibliográficas y entrevistas que resultaron em talleres sobre Turismo y Medio Ambiente. Los talleres ocurrieron em escuelas regulares com La participación de alumnos de los octavos y novenos años de La enseñanza regular.

\section{PALABRAS CLAVE}

Educación. Medio Ambiente. Turismo. 


\section{INTRODUCÃO}

Por meio da educação é possível lançar as primeiras sementes das mudanças sociais, começando pela escolha da profissão, respeito a si mesmo, ao próximo e ao meio ambiente. Pensando nisso foi criado o Projeto Sensibilizando para o Turismo, visando sensibilizar discentes de escolas Públicas para a Importância do Turismo e da Preservação Ambiental, e paralelamente divulgar os cursos técnicos de Guia de Turismo e Meio Ambiente do Instituto Federal de Educação de Alagoas, campus Marechal Deodoro.

Diante da vocação econômica da região de Marechal Deodoro-AL, voltada para a Indústria do Turismo observa-se que o atrativo turístico mais relevante é o Natural. A comunidade é um dos atores do processo turístico e, também, um dos responsáveis pela preservação do meio ambiente. Discentes de escolas públicas da região além de pertencerem à comunidade são atingidos diretamente pela economia local, podendo se tornar novos agentes de desenvolvimento e, ainda, futuros discentes do Instituto Federal de Educação de Alagoas, campus Marechal Deodoro.

0 projeto teve como meta sensibilizar discentes do $7^{\circ}$ ao $9^{\circ}$ ano de escolas Públicas do entorno de Marechal Deodoro; Informar sobre os impactos positivos e negativos do Turismo na comunidade e mostrar a importância da preservação ambiental e formas de contribuição individual e coletiva para isso. Foi elaborado por uma docente e desenvolvido por dois discentes do curso de Guia de Turismo, um discente do Curso de Gestão Ambiental e teve a duração de seis meses.

Após a seleção dos bolsistas, identificação das escolas e turmas participantes, elaborou-se o material para ser trabalhado em oficinas com os alunos das escolas participantes e, ainda, de acordo com as características gerais de cada série trabalhada. As escolas foram selecionadas e contatadas para agendamento das atividades, nas datas designadas os bolsistas do IFAL foram até as escolas para as atividades programadas. Ao final de cada atividade os alunos participantes receberam o material educativo e os bolsistas retornaram para o IFAL. Durante o projeto os discentes prepararam o material educativo, as apresentações e relatórios parciais de atividade, ao final foi elaborado relatório final.

\section{TURISMO E 0 MEIO AMBIENTE}

A existência do homem e a necessidade de produzir seus meios de vida são os pressupostos da evolução histórica do trabalho humano. A partir do momento que o homem se tornou sedentário, alterou suas atividades de produção para reprodução dos bens necessários à sua sobrevivência. No trabalho ele define o seu modo de produção e compõe novas formas ao espaço geográfico.

De acordo com Moreira (1994, p. 85-86) 0 espaço geográfico é a materialidade do processo do trabalho. É a "relação homem-meio" na sua expressão historicamente concreta. "[...] 0 processo do trabalho é a transformação da natureza em produtos úteis aos homens". Assim, considera-se que a história da vida do homem está vinculada à história da natureza, numa relação impossível de dissociar. O homem historicizando a natureza e esta naturalizando o homem.

Sobre o turismo, não se pode iniciar a atividade turística sem a estrutura do "Produto Turístico" formatado. Para tanto Mário Beni (2001, p. 26) coloca

\footnotetext{
[...] o produto turístico é o resultado da soma de recursos naturais e culturais e serviços produzidos por uma pluralidade de empresas, algumas das quais operam a transformação da matéria-prima em produto acabado, enquanto outras oferecem seus bens e serviços [...] a demanda é gerada pelos clientes potenciais, que estão dispostos a consumir o produto mediante a propaganda de seus atributos.
} 
Segundo este autor, a atividade turística tem início a partir de um atrativo, na maioria das vezes natural, que a princípio é frequentado por jovens, depois passa a ser visitado por pessoas de classe social alta, com suas necessidades de consumo que atraem os investidores. Na sequencia, a classe média, também, inicia um processo de visita, e finalmente as classes sociais mais baixas chegam, muitas vezes encontrando o atrativo já bastante degradado, isso pode ser visualizado em diversas localidades do país, como Balneário Camboriú-SC, Porto Seguro-BA, Porto de Galinhas-PE. Estas cidades se encontram em níveis distintos do processo de desenvolvimento turístico.

Estes atrativos naturais são percebidos pela paisagem que apresenta características propícias à visitação pública. 0 turista irá desenvolver inicialmente como lazer, a apreciação e o usufruto das potencialidades oferecidas por este ambiente, e, consequentemente outras atividades oferecidas pela infraestrutura existente naquela paisagem do lugar.

Tomando por base os dados da Organização Mundial do Turismo (OMT) sobre a sua contribuição ao desenvolvimento econômico, nota-se que o turismo é a atividade que mais cresce no mundo, gerando mais emprego e renda do que muitas atividades propulsoras da economia mundial. Porém, esse crescimento muitas vezes é acompanhado de diversos impactos negativos, entre eles o ambiental. Nem sempre o turismo será a solução para problemas econômicos das localidades, em muitos casos ele passa a ser o causador dos mesmos, como a degradação ambiental e até mesmo a extinção dos recursos naturais em algumas regiões.

Um aspecto negativo para o turismo são os impactos socioambientais que ocorrem em diversos aspectos, como: o lixo gerado, o esgoto produzido, a poluição do ar, das águas, a visual, sem contar com a descaracterização cultural que acomete as comunidades.
De acordo com Ruschmann (1997, p. 108),

Para prevenir os impactos ambientais do turismo, a degradação dos recursos e a restrição do seu ciclo de vida, é preciso concentrar os esforços em um desenvolvimento sustentável não apenas do patrimônio natural, mas também dos produtos que se estruturam sobre todos os atrativos e equipamentos turísticos.

Assim, considera-se que o desenvolvimento do turismo só ocorrerá com planejamento e participação comunitária. Definindo o respeito ao meio ambiente natural e a harmonia entre a cultura e os espaços sociais da comunidade receptora, priorizando-se o turismo com ações voltadas para uma situação, não utópica, mas ideal de trabalho.

Até agora o modelo de desenvolvimento turístico foi baseado em turismo de massa, com algumas exceções de ecoturismo, e turismo de elite. Nesse modelo há um favorecimento às grandes redes hoteleiras, companhias aéreas, e operadores turísticos, caracterizando o monopólio e oligopólio do setor. É um modelo que exige vários investimentos em infraestrutura por parte do governo e empresários, e em alguns casos, como Porto Seguro e Balneário Camboriú, mostrou-se ineficiente na questão ambiental e cultural.

No entanto, aponta-se que há espaços para todo tipo de produção que com preparação e financiamento adequados, a comunidade pode ser mobilizada e implantar pequenos empreendimentos ligados ao setor turístico, formando assim uma rede de desenvolvimento sustentável na localidade, e a renda proveniente do turismo seria mantida, em grande parte, no próprio local.

Refletindo sobre as tendências para o desenvolvimento do turismo, Ruschmann (2000, p. 164) aponta que,

\footnotetext{
A extrema valorização dos aspectos econômicos do turismo tem negligenciado os estudos e a consideração dos aspectos relacionados com o meio ambiente natural, a cultura e os aspectos psicossociais das comunidades receptoras.
} 
Segundo Ruschmann (2003, p.110) o turismo de massas é "caracterizado por um grande volume de pessoas que viajam em grupos ou individualmente para os mesmos lugares, geralmente nas mesmas épocas do ano". Dessa forma torna-se perceptível as grandes alterações que este tipo de turismo pode provocar no meio ambiente natural e nas localidades nas quais ele ocorre. Tendo em vista os impactos causados pelo excesso de pessoas que passam a frequentar os mesmos lugares num mesmo espaço de tempo.

0 impacto do turismo sobre o meio ambiente segundo recomendações de Dias (2003 p. 21), é inevitável. 0 que se pretende é mantê-lo dentro dos limites aceitáveis, para que não provoque modificações ambientais irreversíveis e não prejudique o prazer do visitante ao usufruir o lugar. Deve-se considerar, por outro lado, que o turismo não pode ser tratado como o único vilão, pois, existem outros processos econômicos que contribuem para as modificações ambientais nos locais turísticos, e que muitas vezes deixam de ser considerados. É necessário implantar o planejamento turístico para se evitar maiores problemas.

Segundo Beni (2001, p. 60), para se promover a conservação dos recursos turísticos naturais, e planejar a atividade turística deve-se aplicar algumas normas. Planejar o uso dos recursos turísticos naturais com base em planos, projetos, programas e atividades harmônicas com sua quantidade e qualidade. Proteger os recursos que estão em risco de extinção, mediante a proibição de caça, pesca e extração vegetal. Rever e corrigir os erros de manejo em ecossistemas alterados com programas de reflorestamento, combate de pragas, regeneração do solo, e tratamento de água. Aproveitar totalmente um recurso, evitando seu desperdício e aumentando sua quantidade e qualidade. Utilizar um recurso tantas vezes quantas sejam possíveis, inclusive adotando a utilização de outros recursos em substituição daqueles que estão em vias de extinção e a satisfação de várias necessidades mediante um só recurso, isto é, o uso múltiplo.
De acordo com Ferreira (1988, p. 233-234) ecologia é:

1. Parte da biologia que estuda as relações entre os seres vivos e o meio ambiente em que vivem, bem como as suas recíprocas influências; 2 . Ramo das ciências humanas que estuda a estrutura e o desenvolvimento das comunidades humanas em suas relações com o meio ambiente e sua consequente adaptação a ele, assim como novos aspectos que os processos tecnológicos ou os sistemas de organização social possam acarretar para as condições de vida do homem.

A ocupação turística precisa, portanto, acontecer baseada em ecologia, estética, sociedade e planejamento, sendo este último o fiel da balança do desenvolvimento sustentável que pode ocorrer ou não no núcleo turístico em questão. A estética é premissa para o turismo, pois somente com sua existência é que se inicia o processo de visitação e exploração turística. 0 homem sempre busca o belo, 0 agradável para seus momentos de lazer e recreação, porém ele mesmo contribui para que a descaracterização do belo ocorra, ignorando aspectos importantes da ecologia, como deixar intacto tudo aquilo que ele encontrou é a cultura da "lembrancinha" perpétua. Isso reflete um pensamento humano baseado no pressuposto de que só ele fará aquilo, ou seja, ninguém irá repetir o seu gesto.

O turismo ao longo da história evoluiu em harmonia combinada com a estrutura econômica da sociedade e do seu desenvolvimento tecnológico, pois a economia estabelece classes sociais diferenciadas e com poder aquisitivo para viver de acordo com seus desejos e modismos.

$$
\text { De acordo com Trigo (1999, p. 52), }
$$

0 ato de se deslocar geograficamente implica contatar culturas diferenciadas. Quem viaja não pode ser xenófobo ou etnocentrista. Precisa compreender que não existem costumes universais. Há o mundo multifacetado, pluralista e extremamente variado, especialmente quando transformado pelas novas tecnologias.

O desenvolvimento tecnológico estabelece como essas classes vão saciar seus desejos e consequentemente praticar o lazer viajando. É fato que o turismo só se desenvolveu mais intensamente, após a revolu- 
ção industrial (Séc. XVIII), com a modernização dos meios de transportes e comunicações, quando tiveram início as primeiras viagens organizadas.

No Brasil, o turismo como fenômeno social surgiu após 1920, e sempre foi muito sedimentado no lazer externo, e, apesar de ser classificado como "de massa", nunca atingiu o total da população local. Diferente do turismo europeu que possuía cunho educativo ou de aventura e atingia uma grande parcela de sua população. Há poucas instituições preocupadas com o turismo social, e a crise financeira que se arrasta por décadas no país, não permite que uma grande parcela da população tenha acesso às viagens de longa distância ou duração.

Na década de 1970 os Estados do Norte e Nordeste brasileiros lançaram-se no turismo nacional e internacional focando "sol e praia", diferenciando-se das badaladas praias do Sul e Sudeste do país onde a temperatura ambiente e as águas termais, além da beleza cênica atraíam turistas de diversas áreas do mundo.

Na década de 1980 inicia-se o incentivo ao turismo receptivo e ao turismo social por parte de algumas grandes indústrias e governantes com a criação de colônias de férias. No entanto, até o início da década de 1990, no Brasil o turismo era tratado de forma amadora. Os diversos planejamentos realizados não proporcionaram resultados satisfatórios. Apesar disso, o fenômeno econômico gerador de divisas vem crescendo desordenadamente, e os Estados na urgência de organizarem a sua economia, bem como o atendimento às normas da preservação ambiental, priorizam a organização de espaços turísticos geradores de renda e entretenimento com sustentabilidade socioambiental.

De acordo com Trigo (1999) a sociedade pós-moderna exige, entre outras coisas, qualidade nos produtos que consome. É uma sociedade indiferente, individualista, cética, que vivenciou experiências diversas com guerras e terrorismo, e hoje busca emo- ções fortes, porém controladas, uma sociedade que acredita no concreto, em suas próprias experiências, e coloca em xeque o sistema publicitário.

De acordo com a Organização Mundial do Turismo (2003: 30-31),

Se for cuidadosamente planejado, ordenado e gerenciado, o turismo pode levar benefícios substanciais às comunidades locais (...). (...) Sem o devido planejamento, desenvolvimento e gerenciamento, porém o turismo pode resultar em problemas para a área local.

Porém, o desenvolvimento do turismo implica em impactos, que são a gama de modificações ou a sequencia de eventos provocados pelo processo de desenvolvimento turístico nas localidades. As variáveis que provocam os impactos têm natureza, intensidade, direções e magnitude diferentes, porém os resultados interagem e são geralmente irreversíveis quando ocorre no meio ambiente natural.

0 turismo engloba ainda impactos em outras áreas, como a cultural e a ambiental, pois diversos são os aspectos das viagens pelas quais o turista conhece a vida e o pensamento da comunidade receptiva. Esses impactos permeiam o positivo e o negativo na ocorrência da atividade turística. Pois, segundo Beni (2001), Barreto (1999) e outros autores, os atrativos de uma localidade compõem-se do natural e do cultural, sendo que assim, a necessidade da preservação dos mesmos é imprescindível para a continuidade do processo turístico, bem como da vida sustentável da comunidade.

Os reflexos deste impacto se mostram de forma positiva e negativa. Do lado positivo há um aumento da urbanização, um incremento das indústrias associadas de transportes, alimentação, souvenires, demanda de mão de obra para serviços turísticos, mão de obra da construção civil e um aumento da demanda local de hortifrutigranjeiros. A conservação do patrimônio com a reafirmação da identidade cultural, intercâmbio cultural, conservação de áreas naturais importantes, conservação de lugares históricos e ar- 
queológicos, bem como do patrimônio arquitetônico local. Há também melhoria da qualidade do meio ambiente, da infraestrutura, aumento da consciência sobre o meio ambiente, criação de áreas protegidas, entre outros (BARRETO, 1999).

Porém, os impactos negativos que o turismo proporciona para uma comunidade, segundo Barreto (1999) e Beni (2001), podem ser relacionados à: pressão inflacionária devido à concentração de demanda em períodos muito curtos, elevando os preços dos produtos e serviços básicos. Mudanças estruturais de algumas atividades em função da presença da atividade turística e a dependência econômica do turismo com a comercialização excessiva. Há também a perda da autenticidade das manifestações culturais com mudança da identidade cultural, mediante influências no estilo de vida tradicional.Modificações dos padrões de consumo da comunidade a partir da influência dos hábitos dos turistas, despertando necessidades econômicas até então desconhecidas. Relacionamento conflituoso entre hotel e hóspedes devido a mal-entendidos relacionados a diferenças de idioma, costume, valores e padrões de comportamento. Aumento da população residente e sazonal, e consequente perda das comodidades dos habitantes resultando num aumento dos problemas sociais como: drogas, crime e prostituição. Bem como aumento das agressões ambientais como: poluição da água, do ar, sonora e visual; problemas de saneamento básico, degradação ecológica, danos aos lugares históricos e arqueológicos e relativos ao uso e à ocupação do solo.

De acordo com a OMT (2003, p. 24), o desenvolvimento do turismo sustentável é aquele que:

Atende às necessidades dos turistas de hoje e das regiões receptoras, ao mesmo tempo em que protege e amplia as oportunidades para o futuro. É visto como um condutor ao gerenciamento de todos os recursos, de tal forma que as necessidades econômicas, sociais e estéticas possam ser satisfeitas sem desprezar a manutenção da integridade cultural, dos processos ecológicos essenciais, da diversidade biológica e dos sistemas que garantem a vida.
Tendo como princípios a sustentabilidade econômica, sociocultural e ambiental. Na sustentabilidade econômica deve-se assegurar que o desenvolvimento seja eficiente para a sociedade e que os recursos devem ser geridos de maneira que possam manter a geração presente e as gerações futuras. Na sustentabilidade sociocultural deve-se assegurar que o desenvolvimento aumente o controle das pessoas sobre suas próprias vidas, e preserve a cultura e os valores da comunidade, reforçando a identidade comunitária. Já na sustentabilidade ecológica deve-se assegurar que o desenvolvimento seja compatível com a manutenção do processo ecológico essencial, com a diversidade biológica e com os recursos biológicos.

\begin{abstract}
Os conceitos de desenvolvimento sustentável e de turismo sustentável estão intimamente ligados à sustentabilidade do meio ambiente, principalmente nos países menos desenvolvidos. Isso porque o desenvolvimento e o desenvolvimento do turismo em particular dependem da preservação da viabilidade de seus recursos de base. Encontrar o equilíbrio entre os interesses econômicos que o turismo estimula e um desenvolvimento da atividade que preserve o meio ambiente não é tarefa fácil, principalmente porque seu controle depende de critérios e valores subjetivos e de uma política ambiental e turística adequada - que ainda não se encontrou no Brasil e em vários outros países. (RUSCHMANN, 1992, p. 44).
\end{abstract}

A partir dos discursos ecológicos de proteção e preservação do meio ambiente, surgiu uma nova sociedade que desgastada do mundo moderno, onde a tecnologia avançada proporcionou uma poluição generalizada (do ar, do solo, da água, sonora, auditiva, visual etc.) da zona urbana. Nasce daí uma sociedade que sente necessidade de rever as formas primitivas naturais. Conhecer seu conteúdo em lugares onde até então nunca havia vivido ou pensado para seu lazer e entretenimento.

Neste momento a subjetividade dessa sociedade, com a segurança que o mundo moderno the oferece, está buscando novas formas de prazer e dentro delas está o lazer e o entretenimento longe de sua "base operacional" como se pode denominar, o local de residência e trabalho do homem capitalista contemporâneo. 
Essa busca o leva a um reencontro com a natureza, com o cosmos. 0 turismo ecológico ou os esportes radicais remetem o homem ao "paraíso perdido", ao passado, ao sentir e dar prazer.

O prazer em uma viagem de turismo possibilita o homem ao encontro de novos significados para a vida cotidiana, que irá alterar sua vida futura, assim o turismo tem a virtude de atingir a pessoa nos seus mais profundos sentimentos. "O prazer de viajar nasce da expectativa, da procura do prazer que se situa na imaginação e não no real. [...] A realidade jamais propicia os prazeres aperfeiçoados com que o indivíduo se depara nos devaneios" (URRY, 1996, p. 29-30).

Para que ocorra o turismo é necessário que, além dos atrativos naturais ou culturais exista, também, uma infraestrutura razoável para receber o turista. 0 núcleo receptor, que é o lugar que recebe o turista necessita de uma série de equipamentos e serviços denominados turísticos e de apoio. Os equipamentos e serviços turísticos são as chamadas instalações básicas para o turismo, e que sem elas torna-se difícil o desenvolvimento do mesmo, como hotéis, alojamentos diversos, transportadoras, agências, guias de turismo, agentes de recreação, entre outros. Já os equipamentos e serviços de apoio são aqueles que oferecem a segurança necessária e útil para a população e consequentemente para o turista, como hospitais, postos de combustível, rede bancária, souvenires, telefonia, etc.

Além disso, qualquer núcleo receptor precisa ainda da infraestrutura de acesso e básica urbana que são as estradas, asfalto, energia elétrica, limpeza pública, esgoto, aeroportos, entre outras facilidades, que em primeiro lugar beneficia a comunidade, mas também atenda ao turismo.

O importante é utilizar o turismo como uma ferramenta para promover as relações culturais e valorizar as localidades turísticas pelos seus fatores culturais. Desta forma o turista se realiza ao conhecer outras culturas, ao tempo em que se preservam as localidades e mantém-se a geração de emprego e renda, um dos bons resultados da atividade turística.

Se a ordem social revela o perfil de uma civilização, estamos presenciando a lenta mudança desta sociedade capitalista, onde o nível de exigência do consumidor está cada vez mais alto, e começaram a surgir ilhas de oxigênio em meio ao preconceito poluidor, exemplo disto são os hotéis para o público GLSBT, só para mulheres, adultos, crianças, entre outros. É uma abertura que pode significar as mudanças desta sociedade. Esta sociedade, também, está mais exigente em relação ao desenvolvimento, e hoje não basta oferecer um produto bonito, mas também deve ser funcional, responsável socialmente e ecologicamente.

O espaço turístico é pensado pela Organização Mundial do Turismo que declara,

\begin{abstract}
Há uma estreita conexão ente o turismo e o meio ambiente em vários aspectos. Muitos elementos do ambiente natural e do construído são atrativos para os turistas, e o turismo pode auxiliar na conquista da proteção do meio ambiente. As instalações e a infraestrutura turística constituem parte do ambiente construído, e o desenvolvimento turístico e a utilização de uma área pelos turistas são capazes de gerar tanto impactos ambientais positivos quanto negativos. Por último, o nível geral de qualidade ambiental da área turística é tão importante para os residentes como para os turistas. (OMT, 2003, p. 105).
\end{abstract}

Desenvolver de forma sustentável parece ainda um sonho remoto, apesar de a expressão figurar no mundo há aproximadamente duas décadas, as nações ainda não conseguiram estabelecer planos e parâmetros para este desenvolvimento. Os confrontos entre a economia e conservação e proteção do patrimônio ecológico e cultural têm nos mostrado que o capitalismo impera nas decisões e o meio ambiente vem perdendo significativas batalhas nos países desenvolvidos. Pode ser que a fórmula para desenvolver, sem deteriorar o patrimônio cultural, os recursos naturais e o meio ambiente, ainda não tenha sido encontrada. 
Entretanto, já existem inúmeras tentativas e a percepção de alguns países e dos turistas já se mostra mais aguçada, para a busca por modelos em que administrar significa utilizar com a renovação simultânea dos recursos, e ainda encontrar formas de utilizar os recursos para que se renovem e se regenerem mais rapidamente.

\section{MÉTODO}

Este estudo consiste em um relato de experiência vivenciado pela docente da disciplina Marketing e Vendas de Produtos Turísticos, do Curso Técnico Integrado de Guia de Turismo e da disciplina de Gestão Ambiental do Curso Técnico Integrado de Meio Ambiente do Instituto Federal de Alagoas campus Marechal Deodoro, em 2012, duas discentes do Curso Técnico Integrado de Guia de Turismo e um aluno do curso Técnico Integrado de Meio Ambiente.

Para estudar o turismo e a sua complexidade torna-se necessário o uso de instrumentos que permitam uma abordagem multidisciplinar, com base em novas abordagens como a "Teoria dos Sistemas de Turismo" (BENI, 2001, p. 17-19), "onde a realidade é feita de sistemas, que são feitos de elementos interdependentes. A realidade não é feita de elementos isolados, sem qualquer relação entre si”. Esta abordagem permite uma integração dos diversos elementos que compõe o turismo, como o meio ambiente e suas relações.

A fim de abordar adequadamente o tema deste estudo, o trabalho de coleta de informações exigiu a adoção de procedimentos e recursos diversos. Os estágios da pesquisa se dividiram em pesquisa teórica e prática. Para desenvolver a pesquisa teórica foi realizado levantamento bibliográfico em trabalhos acadêmicos e livros.

Como recurso metodológico, foram realizadas a observação participante e a entrevista pessoal desestruturada, as quais se interagem diante da possibilidade que, de seus resultados se obtém maior contribuição no processo do estudo em pauta.
No que se refere ainda à sistematização desse processo o projeto foi elaborado pela discente, aprovado pela Pró-Reitoria de Pesquisa e Extensão do Instituto Federal de Alagoas. Após a aprovação foi realizada uma seleção entre discentes dos referidos cursos técnicos. Os selecionados passaram a se reunir todos os dias após as aulas para realizar pesquisa sobre os temas, produzindo então uma oficina para discentes dos oitavos e nonos anos das escolas públicas. Foi realizada uma pesquisa bibliográfica sobre os temas, após essa primeira fase os discentes entrevistaram os pedagogos da escola para falar sobre educação de crianças e jovens, buscando levantar métodos para interagir melhor com os discentes das escolas. Ao final foi produzido um material educativo, abordando elementos do turismo e meio ambiente, distribuído para os alunos das escolas selecionadas.

Paralelamente foram pesquisadas e selecionadas escolas do entorno do Instituto, deu-se preferência pelas escolas que ainda não tinham sido contempladas com outros projetos de extensão do campus. As escolas selecionadas foram: Escola Municipal Vila Altina Ribeiro Toledo - Situada no Povoado Vila Altina s/n; Escola Municipal Dr. Silvério Jorge - Situada na Av. Benedito Agnelo de Lima, 135, Bairro Pedras; Escola Municipal Maria Petronila de Gouvêa - Situada na Rua Petronila s/n, Bairro Massagueira; Escola Municipal Professora Adelina de Carvalho Melo - Situada na Rua Adelina de Carvalho Melo, Itha de Santa Rita. Entendemos que os discentes bolsistas selecionados para atuar no projeto deveriam agir em todos os processos, incluído o contato com as escolas e realização das oficinas.

As escolas contatadas mostram-se bastante receptivas, e as oficinas, que inicialmente abrangeriam uma turma de cada ano, acabaram sendo realizados com todas as turmas de oitavos e nonos anos das referidas escolas, sendo assim, o projeto precisou ser ampliado na sua execução. Percebemos que entre a docente e os discentes foi construída uma relação de corresponsabilidade pelas ações implementadas, le- 
vando a um maior interesse e comprometimento dos discentes em sala de aula. A percepção dos bolsistas diante das posturas das escolas superou a expectativa inicial, isso se manifestou nos relatórios finais.

\section{RESULTADOS E DISCUSSÕES}

Os discentes bolsistas mostraram nos seus relatórios finais os resultados encontrados em cada escola participante: Na Escola Municipal Vila Altina Ribeiro Toledo as palestras e dinâmicas foram bem recebidas pela gestão da escola e pelas turmas de $8^{\circ}$ e $9^{\circ}$ ano, que receberam o projeto juntos, e apresentara bom retorno e interação de discentes e professores nas atividades executadas.

$\mathrm{Na}$ Escola Municipal Doutor Silvério Jorge as atividades foram divididas em duas etapas, a primeira visita com as turmas de $9^{\circ}$ ano e segunda com as turmas de $8^{\circ}$ ano. Essa divisão se deu por uma questão de tempo disponível por dia e foram realizadas duas visitas. Constatamos que o $8^{\circ}$ ano obteve uma participação mais assídua que o $9^{\circ}$ ano, o possível motivo é o envolvimento de discentes do $8^{\circ}$ ano em projetos de educação ambiental desenvolvido pela própria escola.

$\mathrm{Na}$ Escola Municipal Professora Adelina de Carvalho Melo as atividades, também, foram divididas em duas etapas, sendo observado um baixo aproveitamento motivado pela falta de interesse e participação dos discentes durante as atividades. É importante destacar que essa escola possui uma média de idade menor que as outras, entretanto alguns discentes se sobressaíram e mostraram ter interesse com dúvidas durante as atividades, o que gerou brincadeiras dos outros discentes, justificadas pela pouca idade da maioria dos participantes.

Na última escola, a Escola Municipal Petronila de Gouvêa foi percebido que a mesma passa por problemas políticos e estruturais, contudo, isso não refletiu no andamento do projeto, que foi executado em duas etapas no mesmo dia. Os discentes apresentaram ótimo retorno e interação por meio de discussões sobre os temas apresentados.

A postura e o envolvimento dos discentes bolsistas sofreram alterações no decorrer do projeto. A dedicação aumentou, bem como a participação em sala, as faltas foram reduzidas ou quase eliminadas e o interesse dos mesmos em relação à profissão, a questões sociais e às outras disciplinas dos cursos tornou-se bem acentuado.

As falas dos bolsistas ao final do projeto mostrou um amadurecimento, esses são alguns relatos: "A inserção que me foi dada ao projeto de extensão Sensibilizando para o Turismo despertou em mim grande interesse por assuntos relacionados à educação infantil. - Pude perceber de perto as limitações e dificuldades do sistema público atual. - Todo o processo de planejamento e execução do projeto foi extremamente empolgante. - A honra de poder ser agente disseminador da ideia de turismo sustentável num município com tanto potencial como Marechal Deodoro foi inigualável. - Ver as reações dos discentes a cada nova visita foi de estrema importância e realização pessoal. - Em suma, a capacidade de por em prática o que vemos no dia a dia da escola, sobre o que tanto falamos que é o turismo, estender os limites da escola à comunidade que é tão desprovida de atenção, foi e é de fato um grande orgulho." Falas dos discentes bolsistas.

Em 2013 os bolsistas se formaram nos cursos técnicos de Guia de turismo e Meio Ambiente. Dos três participantes, um tornou-se funcionário público de uma prefeitura e atua como técnico de meio ambiente, outra se tornou guia de turismo de um grande receptivo de Alagoas e a terceira foi estudar psicologia para trabalhar com educação.

Reflexo do trabalho ou não, no ano de 2013 a procura pelo curso de Técnico Integrado de Guia de Turismo foi, pela primeira vez, maior do que a procura pelo curso Técnico Integrado de Meio Ambiente no campus Marechal Deodoro do Instituto Federal de Alagoas. 


\section{REFERÊNCIAS}

BARRETO, Margarita. Manual de iniciação ao estudo do turismo. 6.ed. Campinas,SP: Papirus, 1999.

BARRETO, Margarita. Planejamento e Organização do Turismo. 4.ed. Campinas: Papirus, 1991.

BENI, Mário Carlos. Análise Estrutural do Turismo. 4.ed. rev. São Paulo: SENAC, 2001.

CERVO \& BERVIAN. Metodologia Científica. 4.ed. São Paulo: MAKRON Books, 1996.

DIAS, Reinaldo. Turismo sustentável e meio ambiente. São Paulo: Atlas, 2003.

FERREIRA, Aurélio Buarque de Holanda. Dicionário Aurélio Básico da Língua Portuguesa. Rio de Janeiro: Nova Fronteira, 1988.

MOREIRA, Ruy. 0 que é Geografia. 14.ed. São Paulo: Brasiliense, 1994 (Coleção primeiros passos; 48).

Recebido em:18 de Junho de 2014 Avaliado em: 24 de Junho de 2014 Aceito em: 7 de Julho de 2014
OMT. Guia de desenvolvimento do turismo sustentável. Porto Alegre: Bookman, 2003.

RUSCHMANN, Dóris Van de Meene. Turismo e planejamento sustentável: A proteção do meio ambiente. 6.ed. Campinas, SP: Papirus, 2000 (Coleção Turismo).

RUSCHMANN, Dóris Van de Meene. O desenvolvimento sustentado do turismo. Revista turismo em análise 3 (1). São Paulo, ECA/USP, maio 1992, p.42-50.

TRIGO, Luiz Gonzaga Godoi. Turismo e Qualidade: Tendências contemporâneas. 4.ed. Campinas, SP: Papirus, 1999 (Coleção Turismo).

URRY, John. 0 olhar do turista: lazer e viagem nas sociedades contemporâneas. São Paulo: Estúdio Nobel - SESC, 1996.
1. Mestra em Geografia, Professora do Instituto Federal de Sergipe IFS- ITB ibianchini@yahoo.com.br

2. Especialista em Gestão de Turismo e Hospitalidade, Professor do Instituto Federal de Sergipe, lucagourmet@hotmail.com

3. Doutora em Geografia, Professora do Instituto Federal de Sergipe, lemoraes@hotmail.com

4. Especialista em Educação, Professor, Secretaria de Estado de Educação SE, jobs@infonet.com.br 